\title{
When mothers have serious mental health problems: parenting as a proximal mediator
}

\author{
Daphna Oyserman ${ }^{\mathrm{a}, *}$, Deborah Bybee ${ }^{\mathrm{b}}$, Carol Mowbray ${ }^{\mathrm{c}}$, Tamera Hart-Johnson ${ }^{\mathrm{c}}$ \\ anstitute for Social Research, University of Michigan, 426 Thompson Ave., Room 5240, Ann Arbor, MI 48109, USA \\ ${ }^{\mathrm{b}}$ Michigan State University, USA \\ ${ }^{\mathrm{c}}$ University of Michigan School of Social Work
}

\begin{abstract}
Maternal mental health $(\mathrm{MMH})$ problems are associated with lack of confidence in one's parenting, overly lax or too harsh discipline, and child academic underperformance. We asked if parenting mediates the effect of MMH problems on academic outcomes even among mothers with serious mental illness $(n=164)$. Structural equation analyses show a significant association between $\mathrm{MMH}$ problems and permissive (lack of parenting confidence, lack of follow through) parenting and verbal hostility as well as worse academic outcomes (school recorded grades, teacher reported behaviour). Permissive parenting completely mediated the direct effect of $\mathrm{MMH}$ on academic outcomes. Further analyses showed that the mediation effect was attributed to a single component of permissive parenting-lack of parenting confidence.

(C) 2004 The Association for Professionals in Services for Adolescents. Published by Elsevier Ltd. All rights reserved.
\end{abstract}

\section{Introduction}

According to the 1999 Surgeon General's Report on Mental Health (US Department of Health \& Human Services, 1999), 4-7\% of American adults will experience an episode of diagnosable mental illness in any given year, and about $40 \%$ will have a diagnosable disorder in their lifetime. Mental health problems are thus relatively common in adulthood. For several reasons this means

*Corresponding author. Tel.: + 7346477622 ; fax: + 7346473652.

E-mail address: daphna.oyserman@umich.edu (D. Oyserman).

0140-1971/\$30.00 (C) 2004 The Association for Professionals in Services for Adolescents. Published by Elsevier Ltd. All rights reserved.

doi:10.1016/j.adolescence.2004.11.004 
that children are not unlikely to have a parent with a mental health problem. First, women with mental illness are just as likely to have children as women in general (Buckley, Buchanan, Schulz, \& Tamminga, 1996; Saugstad, 1989). Second, childbirth itself increases risk of depression, with elevated risk continuing through the early years of parenting (Downey \& Coyne, 1990).

Children of parents with mental illness are at increased risk of problems in school (Davies \& Windle, 1997; Garber \& Little, 1999). Specifically, children of parents with depression are at risk of adolescent academic problems (Billings \& Moos, 1983) and lower GPA (Tannenbaum \& Forehand, 1994), as are children of parents with bipolar disorder (Hammen et al., 1987b).

How might parental mental illness elevate risk to children's academic problems? One possibility is that mental illness interferes with parenting, dampening parental ability to provide a developmentally appropriate childrearing context. Mental illness might reduce parental feelings of efficacy as parents - the feeling that they know what to do and are likely to successfully implement this parenting knowledge (for a review of parenting efficacy, see Coleman \& Karraker, 1997). While mental illness is unlikely to influence those aspects of parenting goals or values that are based in childhood experiences, mental illness might reduce parental responsiveness and/or appropriate demandingness (for a review of distinctions between parenting style, behaviours, and goals, see Darling \& Steinberg, 1993). Because serious mental illness is likely to be episodic and recurrent, parental mental illness is likely to involve more than one developmental phase of a child, resulting in accumulation of risk over time (Hammen, 1997). Another possibility is that risk to children is more sensitively linked to current parental functioning rather than historical diagnosis (see for example, Hammen et al., 1987a). Each of these routes is reasonable, yet previous research has not documented that parenting does indeed mediate the negative effects of maternal mental health $(\mathrm{MMH})$ problems on teen academic outcomes. In the following sections, we review what is known about the relationship between $\mathrm{MMH}$ problems and parenting and the relationship between maternal parenting and teen academic outcomes.

\section{Correlates of maternal mental health problems}

\section{Parenting}

Maternal mental illness is associated with a number of parenting problems, particularly problems in setting appropriate structure while avoiding hostile or negative interchanges (for a review see Oyserman, Mowbray, Allen-Meares, \& Firminger, 2000). The link between mental health problems and parenting has also been made in the general population of low-income mothers: those higher in depression are more likely to perceive the maternal role negatively, and this negative perception of motherhood is related to more use of punishment (McLoyd, Jayaratne, Ceballo, \& Borquez, 1994). When asked about their parenting, a consistent concern raised by mothers with a serious mental illness was how to set appropriate standards without going too far, both because mothers felt worried about their ability to provide appropriate as opposed to overly lax or overly harsh discipline and because mothers were unsure about themselves as parents (Mowbray, Oyserman, \& Ross, 1995).

Such a lack of self-confidence in parenting has been operationalized as part of permissive parenting (Robinson, Mandleco, Olsen, \& Hart, 1995) that includes low structure, low discipline, 
low parental demandingness, and a laissez faire attitude. Permissiveness is the most loosely defined of the parenting constructs - sometimes defined as a warm and non-demanding, or a simply non-restrictive style (Darling \& Steinberg, 1993), permissive behaviours reported in studies of mothers with a mental illness may be based on uncertainty as to how to proceed and feelings of incompetence rather than a value judgment about the optimum methods of child-rearing. Mothers may let children decide because they are not sure they know the right path for their child, because they are not sure they can get their child to comply, or because they believe children should decide for themselves. Maternal feelings of incompetence and lack of parental efficacy (confidence) have been linked with a variety of negative outcomes for children (Coleman \& Karraker, 2000).

\section{Parenting and youth outcomes in diverse samples}

We organize the literature in terms of Baumrind's (1991) typology of permissive, authoritative, and authoritarian ways of being a parent. Her typology (with the revisions suggested by Maccoby and Martin (1983) distinguishing responsiveness and structuring as orthogonal elements of parenting) dominates developmental research on parenting. While parents have been assumed to have a set parenting style that is stable over time, little is known about whether styles are indeed either highly polar opposites or stable over time, situations, and the child's developmental phases (Holden \& Miller, 1999). Indeed, Holden and Miller's review suggests that parents are responsive to the characteristics, behaviour and developmental phase of their children, Holden and Miller's (1999) meta-analysis documented few studies focused on parenting during the phase of interest in the current study - the teen years, 11-18 (only 16\% of studies), but they suggest that parents of adolescents are less warm in their parenting than they are before or after this developmental phase. In across-situation analysis, they found the most difference in parent responsiveness, positive affect and control - the basic elements of parenting style, and the least difference in monitoring - a variable that others have found important when predicting risk of delinquent involvement. Child gender may also prompt differences in what parents do to enact authoritative, authoritarian, and permissive parenting. These authors also note stability across time and across children in parenting variables, arguing for continued use of these parenting constructs, with cautious interpretation of findings.

Therefore, while mindful the concerns raised by Darling and Steinberg (1993) about the empirical difficulty of disentangling parenting goals, specific parenting behaviours or practices and parenting style or global frame, we use the Baumrind general parenting framework to organize our review and measurement of parenting as operationalized in a measure of parenting that distinguishes elements of permissive, authoritarian and authoritative parenting and allows each to be assessed separately. This allows for more specific discussion of the elements of parenting associated with both mental health problems and academic outcomes in our study.

\section{Permissive parenting}

Permissive parents are low in demandingness and may be low in responsiveness or warmth, depending on the operationalization. In the general population, permissive parenting is 
consistently associated with teen academic underachievement in European (Onatsu-Arvilommi \& Nurmi, 1997) and American samples (Pittman \& Chase-Lansdale, 2001). In addition, youth with permissive parents have less adaptive achievement strategies (Aunoloa, Stattin, \& Nurmi, 2000) and, when the permissive parent is of the same sex as the teen, lower levels of self-regulatory behaviour across a variety of domains (Patock-Peckham, Cheong, Balhorn, \& Nagosni, 2001).

\section{Authoritative vs. authoritarian parenting}

While permissive parents are low in structure and may also be low in responsiveness and demandingness, authoritative and authoritarian parents are high in structure. Authoritative parenting is operationalized as high in both warmth (e.g. responsiveness) and structure (e.g. appropriate demandingness and involvement in academic life of the child) and has been shown to have a positive relationship with academic outcomes, especially for European American youth (Darling \& Steinberg, 1993; Paulson, 1994). Conversely, authoritarian parenting is operationalized as high in structure (e.g. demands for obedience) but low in interactive warmth (e.g. explanations for rules are not provided), and has been linked to worse academic outcomes in European Americans (Dornbusch, Ritter, Leiderman, Roberts, \& Fraleigh, 1987). Even though authoritarian parenting, with its more traditional focus on parental authority, may be viewed as normative among low-income African American parents (e.g. Peters, 1988; Randolph, 1995), there is some evidence that, as compared with authoritative parenting, both permissive and authoritarian parenting styles are linked with negative academic outcomes, not only for European American but also for African American youth (Taylor, Hinton, \& Wilson, 1995), perhaps because operationalizations of authoritarian parenting often mix negative and punitive style in addition to directiveness.

Thus research to date consistently shows negative effects of permissive parenting and also suggests that mothers with a mental illness may be more permissive in their parenting. Similarly, some elements of authoritarian parenting (harsh discipline) have been linked to maternal mental illness, and although research on the influence of authoritarian parenting on academic outcomes is less conclusive when non-European American or low-income samples are used, it is likely that harsh discipline will have negative consequences. Moreover, there is evidence that lack of confidence in parenting (and low parenting efficacy) is likely to be an important predictor of child outcomes, because it has been found to mediate the negative effects of parental depression on the mental health outcomes of young children (Cutrona \& Troutman, 1986; Gelfand \& Teti, 1990).

However, research to date has not examined the mediating effect of parenting on the relationship between $\mathrm{MMH}$ and adolescent academic outcomes. Moreover, as noted above, there is some evidence that the effect of parenting on academic outcomes may differ by socio-economic and racial group. Therefore, in the current study we address this gap by studying the mediating effect of parenting practices for academic outcomes of low-income teens whose mothers have a serious mental illness. To increase the robustness of our findings, we use multiple subscales to study permissive, authoritarian and authoritative parenting, allowing each mother to obtain a score on each subscale as well as an overall permissive, authoritarian and authoritative score, examine equivalence of the factor structure of permissive, authoritarian and authoritative parenting across race, gender, and child age group, assess academic outcomes through 
school records of grades and teacher report of behaviour, and use a sample of mothers with at least a year of community mental health $(\mathrm{CMH})$ service receipt and a diagnosis of serious mental illness.

\section{Hypotheses}

Following our review of the literature, we hypothesize that permissive and authoritarian (especially harsh) parenting and $\mathrm{MMH}$ symptoms will be negatively associated with youth academic outcomes and that parenting will mediate the negative effect of maternal mental health difficulties on youth outcomes. Specifically, (1) MMH problems will have negative effects on teen academic outcomes. (2) permissive and authoritarian (harsh) parenting will both have negative effects on teen academic outcomes. (3) The negative effect of $\mathrm{MMH}$ problems on academic outcomes will be mediated by permissive (authoritarian) parenting. That is, mothers with more mental health problems will be more likely to be permissive (authoritarian), and it is permissive (authoritarian) parenting, in turn, that will predict youth academic problems. Our hypotheses are presented graphically in the models displayed in Figs. 1a and $b$.

In addition to specific hypotheses, we explored the relationship between academic outcomes and authoritative parenting and the relationship between $\mathrm{MMH}$ problems and authoritative parenting, since there is insufficient literature to support a specific hypothesis about the role of authoritative parenting with a low income, ethnically diverse sample. We also explored the relationship between parenting and maternal diagnosis, as there is evidence that each diagnosis is related to problematic parenting but insufficient literature comparing across depression, bipolar and schizophrenia to provide the basis for specific hypotheses about differential diagnosis-specific effects on parenting.

\section{Methods}

\section{Participants}

Data from two studies were used in the reported analyses - a study of parenting in women with serious mental illness, and a second companion study of these mothers' teenaged children. Participating mothers $(n=317)$ were racially diverse $(59 \%$ African American, 30\% Caucasian, $8 \%$ Hispanic and $3 \%$ other), with a serious mental illness (duration greater than a year; diagnoses primarily of schizophrenia, major affective disorder, or bipolar disorder; and causing major dysfunction in one or more life areas); all had care-giving responsibilities for least one 4-16 year old child. The CMH management information system initially identified 484 mothers from 12 $\mathrm{CMH}$ agencies and 3 inpatient psychiatric units in southeast Michigan $(n=59$ declined participation and $n=46$ could not be contacted or scheduled), resulting in 379 initial participants. Mothers were interviewed three times over a 4-year period, with a final retained sample of 317 . At initial interview, mothers had open cases with $\mathrm{CMH}$, by second and third interview there was increased heterogeneity in maternal receipt of psychiatric services. Participating mothers ( $M d$ age 36.5 years) were equally likely to have less than a high school education, a high school diploma or 


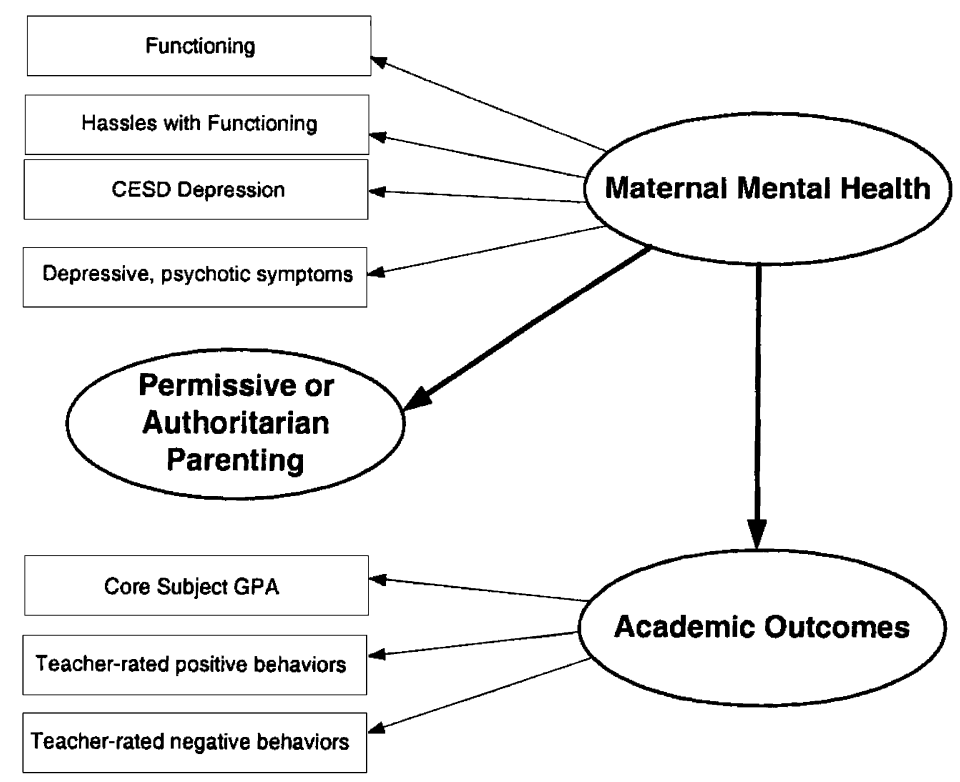

(a)

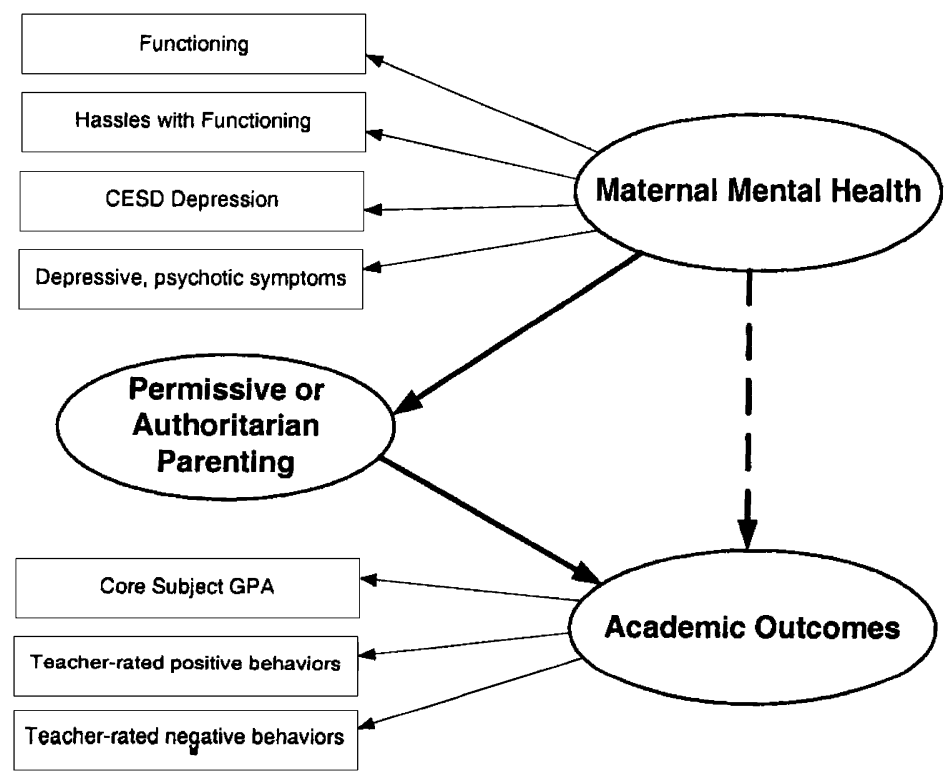

(b)

Fig. 1. Hypothesized models: (a) direct effects model of MMH affecting parenting and youth academic outcomes. (b) mediated effects model of MMH affecting youth academic outcomes through parenting.

GED, or some college education. Incomes were low, averaging 0.95 (s.D. $=0.59$ ) of the federal poverty line, which for a family of two adults and two children was $\$ 15,455$ in 1995 (US Census Bureau, 1996). 
Potential teen participants were aged $11-18(n=237)$. The final sample of 164 excluded $n=31$ parent refused, $n=27$ unable to locate teen after parental consent, $n=11$ teen refused, and an additional 4 interviews discarded due to teen enrollment in non-graded (non-academic) special education classes. The final teen sample $(M a g e=15$, s.D. $=2.04)$ was balanced by sex $(n=85$ males) and was 60\% African American, 30\% non-Hispanic white, and 10\% Hispanic. Mothers of teens were older but otherwise not significantly different in race, income, education or diagnosis from mothers in the full sample.

\section{Procedures}

Maternal data were collected at three time points, with about 22 months between each assessment (Wave 1, demographics and diagnosis, Wave 2, maternal functioning, Wave 3, parenting). We obtained parental permission to contact teens and teachers and to obtain school records; teens were interviewed within 6 weeks following the maternal Wave 3 interview. Teens provided their school name (or school last attended) and the names of the two academic subject teachers who knew them best. We mailed requests for school records and teacher rating of teen behaviour in the academic term that included or was closest to the youth interview and followed up with telephone reminder and in-person pick-up as needed.

\section{Measures}

\section{Maternal measures}

Maternal psychiatric diagnosis (Wave 1) was assessed using the Depression, Mania, and Psychosis sections of the Diagnostic Interview Schedule (DIS, Robins, Helzer, Croughan, \& Ratcliff, 1981), version III-R, modified for DSM-IV criteria. A DIS-trained Ph.D. psychologist conducted the interviewer training for administration of this structured protocol. All interviews were audio taped, and a random 10\% were reviewed for reliability. Diagnoses were assigned by both the interview coordinator (following the DIS algorithm) and the Ph.D. psychologist (using a DIS algorithm for DSM-IV). Differences in diagnostic determinations were identified and discussed to reach a consensus determination for the final diagnosis. Diagnoses were depression $(51.2 \%)$, bipolar disorder $(27.7 \%)$, and schizophrenia/schizoaffective disorder $(21.1 \%)$.

Maternal psychiatric functioning (Wave 2): Maternal functioning assessed maternal engagement in everyday behaviours and activities (managing a household; engaging in productive activity; interacting with others; and controlling one's actions) on an 18-item scale, with responses anchored at $1=$ no activity in the domain, 5=frequent independent activity (Self-Report Community Functioning Scale; Bybee, Mowbray, Oyserman, \& Lewandowski, 2003), $M=3.53$; S.D. $=0.55 ; \alpha=0.80$.

Maternal functioning hassles assessed frequent and relatively mild daily stresses or hassles with cooking and housework, shopping, health, medication and energy on a 5-item scale anchored at $0=$ not $a$ hassle at all and $4=a$ great deal of hassle (Hassles and Uplifts Scale, Lazarus \& Folkman, 1984; see also Hahn \& Smith, 1999), $M=1.98$, s.D. $=0.77, \alpha=0.80$.

CES-D maternal depression assessed depressive symptoms on a 20 -item scale anchored at $0=$ never to less than once this past week, $3=$ at least 5 days this week (Center for Epidemiology Scale for Depression CES-D, Radloff, 1977), $M=22.81$, s.D. $=14.42, \alpha=0.93$. 
MMH symptomatology assessed depressive and psychotic symptoms on a 14-item scale anchored at $1=$ never/not in the last year, $5=$ at least every day/most of the time (Colorado Symptom Index, Shern et al., 1994), $M=2.59$, s.D. $=0.78, \alpha=0.91$.

Maternal parenting (Wave 3): The Parenting Practices Questionnaire (PPQ) assessed authoritarian, authoritative and permissive parenting with 46 items (5-point scale anchored at $1=$ never, $5=$ always) (Robinson et al., 1995), including 4 subscales each to assess authoritarian (verbal hostility, corporal punishment, non-reasoning punitive strategies, directiveness) and authoritative (warmth and involvement, easy going, reasoning/induction, democratic participation) parenting and 3 subscales to assess permissive parenting (lack of follow through, ignoring misbehaviour, lack of parental self-confidence). The PPQ was developed as an operationalization of Baumrind's authoritative, authoritarian, and permissive parenting with multidimensional assessment of each. Robinson and colleagues (1995) have conducted a confirmatory factor analyses to show that the subscales do in fact load as expected on authoritative, authoritarian and permissive parenting. Because their sample composed of predominantly white, non-mentally ill parents of younger children, we also conducted confirmatory factor analyses on our sample for authoritative, authoritarian and permissive parenting.

\section{Youth academic outcome measures}

School records GPA was calculated for core academic classes (English, math, history, science), $M=1.96$ (s.D. $=1.07)$.

Classroom behaviour was assessed through core teachers' ratings of the frequency of 14 behaviours ( 7 positive, 7 negative) on a 5-point scale $(1=$ never, $5=$ always $)$ (Finn, Pannozzo, \& Voelkl, 1995; revision for middle and high school provided by J.D. Finn, personal communication, October 14, 1998). Positive items included paying attention in class, participating in class discussion, $M=3.28$, s.D. $=0.88, \alpha=0.91$, negative items included bothering classmates, coming late, $M=1.75$, s.D. $=0.62, \alpha=0.77$.

\section{Analysis plan}

The analysis used structural equation modelling (SEM) to test the direct and mediated relationships between maternal functioning assessed at Wave 2, parenting assessed at Wave 3, and youth academic outcomes assessed following Wave 3. We included as controls maternal diagnosis, race and gender of youth as each related to at least one latent factor. Directional paths paralleled the timing of data collection as well as the theoretical model positing that $\mathrm{MMH}$ influences parenting and that both $\mathrm{MMH}$ and parenting influence youth academic outcomes.

Before testing the mediational hypotheses, second-order confirmatory factor analysis (CFA) was first used to verify the factor structure of the Maternal Parenting Practices measure as well as the composition of the maternal functioning and youth academic outcome constructs. Parenting scale confirmatory factor analyses utilized the full maternal data set $(n=317)$, whereas testing the structural associations between $\mathrm{MMH}$, parenting and academic outcomes utilized the subset of $n=164$ maternal-teen dyads. To ensure that the parenting measure had equivalent structure and meaning across diverse groups of youth, it was formally tested for factorial invariance by race, child gender and age group, using multi-group CFA methods delineated by Byrne, Shavelson, and Muthen (1989). 
After establishing adequate fit of the factor structure to the data and acceptable levels of measurement invariance, structural models were used to test and interpret specific mediation effects of authoritative, authoritarian, and permissive parenting on the relationship between MMH and youth academic outcomes. We used the general approach to testing mediation outlined by Baron and Kenny (1986) and updated by Holmbeck (1997), using the specific SEM procedures recommended by Brown (1997). Specifically, each parenting construct was first tested for presence of a significant relationship with both of the key constructs-MMH functioning and youth academic outcomes. For each parenting construct that was significantly related to both MMH and youth academic outcomes, alternate models were estimated: in the direct effects model, the path from parenting to academic outcomes was fixed at zero, while it was freely estimated in the mediated effects model (see Fig. 1). The likelihood ratio (LR) $\chi^{2}$ test was used to assess the difference in fit between these nested models, testing whether addition of the mediational path significantly improved model fit for the mediation model (Fig. 1b) relative to the unmediated model (Fig. 1a). The magnitude of the direct effect of MMH on youth academic outcome was also compared for the two models, and the significance of the indirect, mediated effect was tested using bias-corrected bootstrap standard errors (MacKinnon, Lockwood, \& Williams, 2004; Shrout \& Bolger, 2002).

As recommended by $\mathrm{Hu}$ and Bentler (1995), we used maximum likelihood (ML) methods (AMOS 4 software, Arbuckle \& Wothke, 1999), to estimate model parameters and assessed model fit with the indices and thresholds they suggest (Hu \& Bentler, 1998, 1999). Specifically, using as our criteria a standardized root-mean-residual (SRMR; Bentler \& Wu, 1995) of 0.08 or smaller, and root-mean-square error of approximation (RSMEA) of 0.06 or smaller. The data set showed acceptable normality-Mardia's (1985) test for multivariate kurtosis was non-significant for all models; and the sample of 164 was adequate for tests of mediation effects (see Hoyle \& Kenny, 1999). ${ }^{1}$

\section{Results}

\section{Measurement model}

The second-order CFA of parenting generally verified the conceptualized factor structure of the measure as containing three correlated, second-order factors (authoritarian, authoritative, and permissive parenting), each comprised of 3 or 4 first-order factors. However, inspection of loadings and modification indices suggested changes that could improve the fit of the factor structure to the data. First, 4 of the 46 items failed to load significantly on their respective factors,

\footnotetext{
${ }^{1}$ Across all measures, items had relatively normal distributions with the exception of the following parenting items that had kurtosis above 3: 'slapping,' 'calling names,' 'allowing child to interrupt,' 'allowing child to annoy others,' 'giving praise,' 'encouraging child to talk about troubles,' and 'respecting/encouraging child's opinions.' Missing data were estimated using expectation maximization (EM; Schafer \& Graham, 2002). Only 1.8\% of the total data matrix were missing and required estimation; these included teacher ratings that were missing for 12 students (due to teacher mobility, refusal, or inability to remember the student), and GPA that was missing for 13 students (due to school system inability to provide grades for the appropriate term). Overall, missing data appeared to be ignorable (Little's MCAR $\chi^{2}(231)=228.66, p=0.53$; Little \& Rubin, 1990).
} 
and these were removed from further analysis. Second, two first-order components of authoritative parenting-Warmth/Involvement and Relaxed/Easy Going, were highly correlated and had highly cross-loading error terms, suggesting that the two would more appropriately be combined to form a single component, termed Warmth/Easy Going. Finally, one first-order component of authoritarian parenting (Directiveness) failed to load with the other components of authoritarian parenting-Verbal Hostility, Corporal Punishment, and Non-reasoning Strategies, which were highly correlated with each other. Examination of item content led to the observation that these latter components were conceptually distinct and so the third second-order factor was re-labeled Punitive Authoritarian and a fourth second-order factor, Directiveness was formed. Although the resulting CFA was not a perfect fit to the data, as indicted by the significant $\chi^{2}$, it fit adequately, below the thresholds of the fit indices $\left(\Pi^{2}(804)=1607.05, p<0.001\right.$, $\mathrm{RMSEA}=0.06$, $\mathrm{SRMR}=0.08$ ). The resulting 4-factor second-order CFA is summarized in Fig. 2, with the items and associated loadings in Table 1 and correlations in Table 2. All coefficients at both levels were significant at $p<0.01$.

Invariance of loadings by youth race, gender and age group was generally confirmed. Exceptions to complete invariance (i.e. loadings that differed by group and therefore needed to be estimated separately) are noted in Table 1, and the separate within-group loadings are summarized. The general pattern of invariance supported the feasibility of using the items as latent construct indicators with this diverse sample of mothers and their children.

Maternal functioning and academic outcomes CFA was used to examine the adequacy of the remaining latent constructs in the model - the latent maternal functioning construct, created from the four $\mathrm{MMH}$ indicators, and the latent youth academic outcome construct formed from the teacher rating and GPA measures. This CFA showed good fit to the data $\left(\Pi^{2}(23)=32.25\right.$, $p=0.10 ;$ RMSEA $=0.05 ;$ SRMR $=0.04)$, indicating that the constructs were adequate for use in the model.

\section{Structural model}

Race effects were found for report of permissive, directive, and punitive authoritarian parenting - African American mothers were lower in permissive parenting $(\beta=-0.25, p=0.01)$, higher in directive parenting $(\beta=0.33, p=0.001)$ and higher in punitive authoritarian parenting $(\beta=0.20, p=0.04)$, but no different on authoritative parenting $(\beta=-0.06, p=0.54)$. There was a trend-level gender effect on academic outcomes, with boys tending to have worse outcomes $(\beta=-0.20, p=0.08)$. Maternal diagnosis related to significantly to $\mathrm{MMH}$, in that mothers with bipolar disorder were functioning significantly worse than those with either major depression or schizophrenia-related diagnoses $(\beta=-0.19, p=0.02)$. Youth age was not related to any of the latent constructs and was omitted from further analysis.

Using race, gender, and maternal diagnosis as controls, we examined the direct effect of maternal functioning on parenting and on teen academic outcomes as well as the effects of parenting (authoritative, punitive authoritarian, directive, and permissive) on teen academic outcomes. Sample size of the paired mother-child data set $(n=164)$ did not permit inclusion of all four parenting constructs in the model simultaneously, so we examined each separately, adding one latent parenting construct at a time to the structural equation model, testing each as a potential mediator of the effect of maternal functioning on youth academic outcomes. 


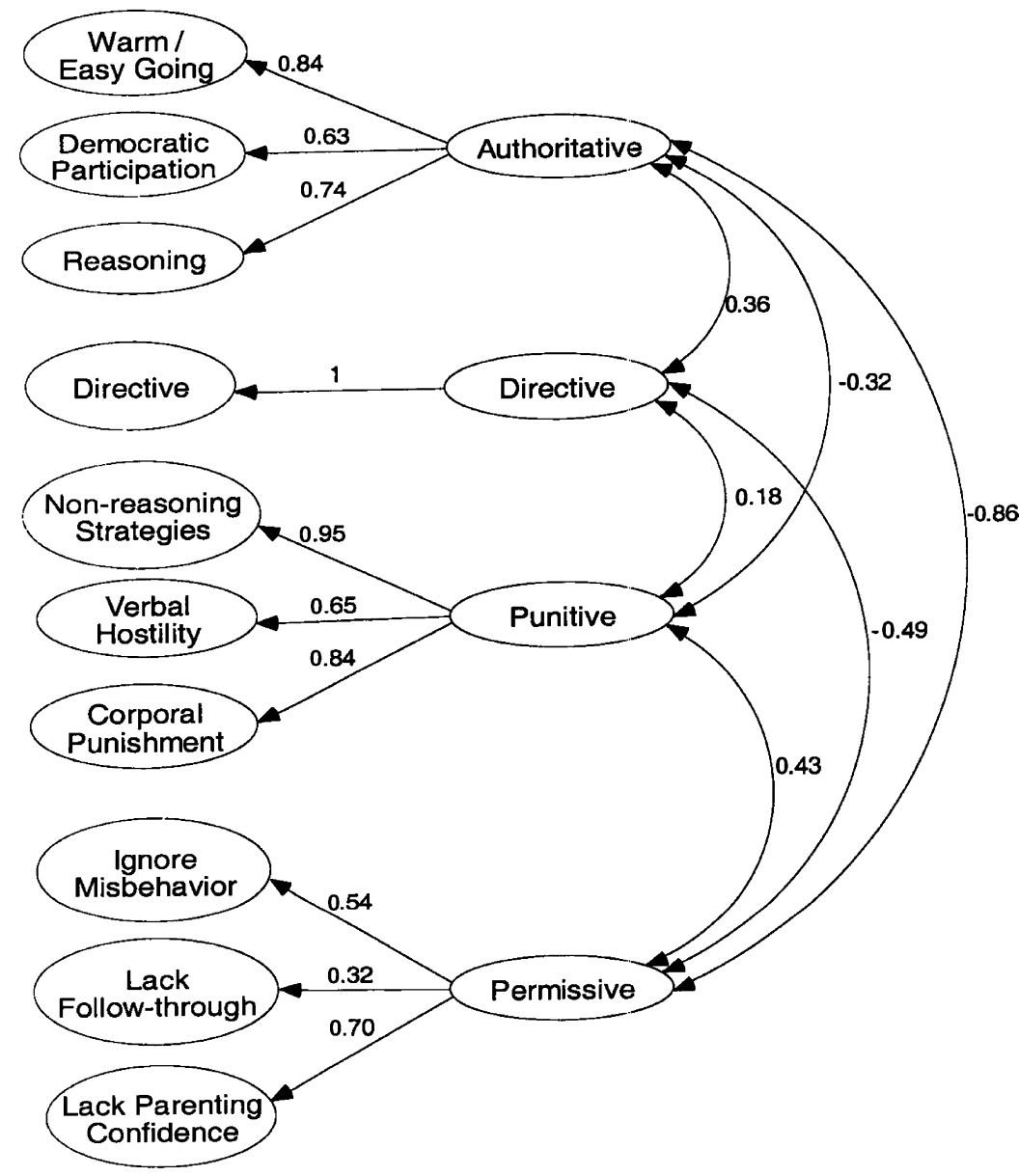

Fig. 2. Second-order confirmatory factor structure for parenting $\left(N=313\right.$ mothers). $\Pi^{2}(804)=1607.05, p<0.001$; $\mathrm{SRMR}=0.081 ; \mathrm{RMSEA}=0.056$. All coefficients are standardized, and all are significant at $p<0.01$. First-order items and loadings are listed in Table 1.

Direct effects of maternal functioning: Applying the direct effects model, illustrated in Fig. 1a, maternal functioning was found to have a significant association with both teen academic outcomes $(\beta=0.27, p<0.01)$ and permissive parenting $(\beta=-0.38, p=0.001)$, but it was not significantly associated with directive $(\beta=0.00, p=0.99)$; authoritative $(\beta=0.15, p=0.14)$, or punitive $(\beta=-0.12, p=0.24)$ parenting. For permissive parenting, fit of the direct effects model was imperfect, as indicated by the significant $\chi^{2}$, but adequate according to the fit index thresholds $\left(\chi^{2}(64)=101.17, p=0.002 ;\right.$ SRMR $=0.080$; RMSEA $\left.=0.060\right)$.

Mediated effects of maternal functioning, via permissive, directive, punitive or authoritative parenting: The mediation model, illustrated in Fig. 1b, added an effect from each latent parenting construct to academic outcomes. This path was significant for permissive parenting $(\beta=-0.29$, $p<0.05)$, but not for directive $(\beta=0.05, p=0.66)$, punitive $(\beta=-0.01, p=0.93)$, or authoritative parenting $(\beta=-0.11, p=0.33)$. For permissive parenting, adding the mediational 
Table 1

First-order confirmatory factor loadings for parenting items $(N=313$ mothers $)$

\begin{tabular}{|c|c|c|c|}
\hline First-order factor & Item & Loading $^{\mathrm{a}}$ & Invariance issue \\
\hline \multirow[t]{8}{*}{ Warm/easy going } & I show patience with my child & 0.61 & \\
\hline & Give praise when child is good & 0.57 & \\
\hline & Easy going \& relaxed with child & 0.55 & \\
\hline & Express affection-hug and kiss & 0.53 & \\
\hline & I respect my child's opinion & 0.52 & \\
\hline & I joke and play with my child & 0.48 & \\
\hline & Sympathetic when child hurt/frustrated & 0.47 & \\
\hline & Encourage child to talk about problems & 0.46 & Race $^{\mathrm{b}}$ \\
\hline \multirow[t]{3}{*}{ Democratic participation } & Account for child's preferences in plans & 0.69 & \\
\hline & Take child's desires into account & 0.56 & \\
\hline & Allow child input into family rules & 0.38 & \\
\hline \multirow[t]{6}{*}{ Reasoning } & I emphasize the reason for rules & 0.71 & \\
\hline & Explain consequences of behaviour & 0.68 & \\
\hline & Help child understand impact of behaviour & 0.66 & Sex; Age $^{c}$ \\
\hline & Explain how I feel re good/bad behaviour & 0.63 & \\
\hline & Give reasons rules should be obeyed & 0.57 & \\
\hline & Reason with child when misbehaves & 0.35 & \\
\hline \multirow[t]{3}{*}{ Directive } & Important that children follow family rules & 0.78 & \\
\hline & Important that children do what you ask & 0.64 & \\
\hline & I have strict rules for my child & 0.39 & \\
\hline \multirow[t]{3}{*}{ Non-reasoning strategies } & Punish by putting child off alone & 0.58 & $\operatorname{Sex}^{\mathrm{d}}$ \\
\hline & I tell my child "Because I said so" & 0.55 & \\
\hline & Discipline first and ask questions later & 0.48 & \\
\hline \multirow[t]{5}{*}{ Verbal hostility } & I don't yell when my child misbehaves & -0.62 & \\
\hline & I insult my child when misbehaves & 0.57 & \\
\hline & I swear when child misbehaves & 0.56 & \\
\hline & Get visibly angry when child misbehaves & 0.55 & \\
\hline & Avoid argument when child misbehaves & -0.34 & $\operatorname{Age}^{\mathrm{e}}$ \\
\hline \multirow[t]{4}{*}{ Corporal punishment } & Grab child when disobedient & 0.77 & \\
\hline & Physical punishment is best discipline & 0.61 & \\
\hline & Spank when my child is disobedient & 0.57 & \\
\hline & Slap child when he/she misbehaves & 0.45 & \\
\hline \multirow[t]{3}{*}{ Ignore misbehaviour } & I allow my child to annoy others & 0.61 & \\
\hline & I ignore my child's misbehaviours & 0.58 & \\
\hline & I allow my child to interrupt others & 0.47 & \\
\hline \multirow[t]{4}{*}{ Lack follow-through } & When I warn, I always do what I say & -0.65 & \\
\hline & Threaten punishments I can't carry out & 0.53 & \\
\hline & I often let my child's behaviours go & 0.38 & \\
\hline & Threaten punishment more than give it & 0.29 & \\
\hline \multirow[t]{3}{*}{ Lack parenting confidence } & I appear confident about how I parent & -0.70 & \\
\hline & Unsure how to solve child's misbehaviour & 0.54 & \\
\hline & I find it difficult to discipline my child & 0.41 & \\
\hline
\end{tabular}

\footnotetext{
${ }^{\mathrm{a}}$ Loadings are standardized; all are significant at $p<0.001$.

${ }^{\mathrm{b}}$ Loading differed by race: raw $B=0.92$ (African American), 0.41 (White/Hispanic).

${ }^{\mathrm{c}}$ Loading differed by sex and age: raw $B=1.41(\mathrm{M}), 0.67(\mathrm{~F}) ; 1.0($ age $<12), 1.84$ (12-15), 0.77 (age $\left.>15\right)$.

${ }^{\mathrm{d}}$ Loading differed by sex: raw $B=1.20$ (Male), 0.61 (Female).

${ }^{\mathrm{e}}$ Loading differed by age: raw $B=-0.46$ (age $<12$ ), -0.38 (age 12-15), -0.99 (age $\left.>15\right)$.
} 
Table 2

Intercorrelations among variables used in SEM analyses $(N=164$ mother-youth pairs)

\begin{tabular}{|c|c|c|c|c|c|c|c|c|c|c|c|c|c|c|c|c|c|c|c|c|c|c|c|}
\hline & Mean & S.D. & 1 & 2 & 3 & 4 & 5 & 6 & 7 & 8 & 9 & 10 & 11 & 12 & 13 & 14 & 15 & 16 & 17 & 18 & 19 & 20 & 21 \\
\hline 1. Bipolar diagnosis & 0.24 & 0.43 & - & & & & & & & & & & & & & & & & & & & & \\
\hline $\begin{array}{l}\text { 2. African American } \\
\text { race }\end{array}$ & 0.62 & 0.49 & 0.02 & - & & & & & & & & & & & & & & & & & & & \\
\hline 4. Youth age & 15.00 & 2.04 & -0.03 & -0.04 & 0.10 & - & & & & & & & & & & & & & & & & & \\
\hline 5. Functioning & 3.48 & 0.51 & -0.13 & -0.04 & -0.07 & 0.08 & - & & & & & & & & & & & & & & & & \\
\hline $\begin{array}{l}\text { 6. Depressive/ } \\
\text { psychotic } \\
\text { symptoms }\end{array}$ & 2.62 & 0.75 & $0.18^{*}$ & 0.02 & 0.01 & -0.07 & $-0.72^{* * *}$ & - & & & & & & & & & & & & & & & \\
\hline $\begin{array}{l}\text { 8. Hassles with } \\
\text { functioning }\end{array}$ & 2.04 & 0.77 & 0.11 & -0.08 & 0.12 & $-0.15^{* * * *}$ & $-0.55^{* * *}$ & $0.41^{* * *}$ & $0.51^{* * * *}$ & - & & & & & & & & & & & & & \\
\hline 9. Warm/easy going ${ }^{\mathrm{a}}$ & 0.00 & 0.61 & -0.02 & -0.05 & -0.11 & 0.08 & $0.16^{*}$ & 0.01 & -0.07 & -0.10 & - & & & & & & & & & & & & \\
\hline $\begin{array}{l}\text { 10. Democratic } \\
\text { participation }^{\mathrm{a}}\end{array}$ & 0.00 & 0.71 & $-0.15^{*}$ & $-0.19^{*}$ & 0.10 & $0.16^{*}$ & $0.15^{\prime \prime}$ & -0.11 & $-0.14^{* * * * 1}$ & $"-0.02$ & $0.37^{* * *}$ & - & & & & & & & & & & & \\
\hline 11. Reasoning ${ }^{\mathrm{a}}$ & 0.00 & 0.67 & 0.01 & $0.14^{* * * *}$ & -0.08 & 0.01 & 0.05 & -0.02 & 0.01 & 0.03 & $0.41^{\text {*** }}$ & $0.36^{* *}$ & - & & & & & & & & & & \\
\hline 12. Directive $\mathrm{e}^{\mathrm{a}}$ & 0.00 & 0.75 & 0.05 & $0.25^{* * *}$ & -0.12 & 0.06 & 0.01 & 0.04 & -0.02 & -0.06 & 0.06 & -0.05 & $0.35^{* * *}$ & - & & & & & & & & & \\
\hline 13. Non-reasoning ${ }^{a}$ & 0.00 & 0.67 & 0.01 & 0.11 & 0.07 & -0.04 & -0.09 & 0.03 & 0.12 & -0.01 & $-0.20^{* * *}$ & -0.09 & 0.09 & $0.15^{* * * *}$ & "- & & & & & & & & \\
\hline 14. Verbal hostility ${ }^{\mathrm{a}}$ & 0.00 & 0.65 & 0.12 & 0.06 & $0.17^{*}$ & -0.09 & $-0.18^{*}$ & $0.13^{* * * *}$ & " $0.16^{*}$ & 0.02 & $-0.43^{* * *}$ & $-0.30^{* * *}$ & $-0.13^{* * * *}$ & 0.04 & $0.42^{* * *}$ & - & & & & & & & \\
\hline $\begin{array}{l}\text { 15. Corporal } \\
\text { punishment }^{\mathrm{a}}\end{array}$ & 0.00 & 0.70 & -0.04 & $0.22^{m * *}$ & -0.04 & $-0.16^{*}$ & 0.04 & -0.06 & 0.01 & -0.06 & $-0.27^{* * *}$ & $-0.26^{* *}$ & 0.01 & $0.15^{* * * *}$ & $0.44^{* * *}$ & $0.36^{* * *}$ & - & & & & & & \\
\hline $\begin{array}{l}\text { 17. Lack follow- } \\
\text { through }^{\mathrm{a}}\end{array}$ & 0.00 & 0.64 & -0.05 & $0.15^{* * * *}$ & 0.00 & 0.08 & $-0.15^{*}$ & $0.17^{*}$ & $0.18^{*}$ & 0.09 & -0.02 & -0.09 & $-0.18^{*}$ & $-0.15^{* * * *}$ & 0.04 & 0.11 & -0.03 & 0.05 & - & & & & \\
\hline $\begin{array}{l}\text { 18. Lack of parenting } \\
\text { confidence }^{\mathrm{a}}\end{array}$ & 0.00 & 0.75 & 0.07 & $-0.20^{*}$ & $0.18^{*}$ & -0.05 & $-0.25^{* * *}$ & $0.24^{* * *}$ & $0.34^{* * * *}$ & $0.29^{* * *}$ & $-0.28^{* * *}$ & $-0.17^{*}$ & $-0.29^{* * *}$ & $-0.20^{* * *}$ & 0.09 & $0.31^{* * *}$ & 0.01 & $0.30^{* * *}$ & $0.25^{* * *}$ & - & & & \\
\hline $\begin{array}{l}\text { 19. Teacher-rated } \\
\text { positive behaviour }\end{array}$ & 3.26 & 0.87 & -0.04 & $0.23^{* * *}$ & -0.12 & 0.09 & $0.14^{* * * * *}$ & $"-0.11$ & $-0.16^{*}$ & -0.12 & -0.12 & -0.09 & -0.10 & 0.04 & 0.01 & -0.03 & 0.09 & -0.04 & 0.05 & $-0.18^{*}$ & - & & \\
\hline $\begin{array}{l}\text { 20. Teacher-rated } \\
\text { negative behaviour }\end{array}$ & 1.75 & 0.60 & $0.15^{* * * *}$ & * 0.01 & $0.13^{* * * *}$ & $"-0.03$ & $-0.21^{* * *}$ & $0.14^{* * * *}$ & " $0.19^{\prime \prime}$ & $0.15^{* * * *}$ & ${ }^{*}-0.08$ & -0.11 & 0.02 & -0.04 & 0.11 & $0.18^{*}$ & 0.00 & 0.09 & -0.03 & $0.23^{* * *}$ & $-0.54^{* * *}$ & - & \\
\hline 21. Core subject GPA & 1.85 & 1.08 & 0.03 & 0.08 & -0.13 & $-0.14^{* * * *}$ & $0.17^{*}$ & -0.07 & $-0.15^{*}$ & -0.12 & -0.04 & -0.06 & -0.02 & -0.06 & 0.02 & -0.04 & 0.09 & -0.03 & -0.07 & $-0.29^{* * *}$ & $0.38^{* * *}$ & $-0.38^{* * *}$ & - \\
\hline
\end{tabular}

Note: ${ }^{*} p<0.05 ;{ }^{* *} p<0.01 ;{ }^{* * *} p<0.10$.

${ }^{\mathrm{a}}$ Items going into parenting style scales were standardized because they had different anchors, so means are 0 . 
path resulted in significant improvement of model fit $\left(\operatorname{LR} \Pi^{2}(1)=4.33, p=0.04\right)$. In the mediated effects model, the indirect effect of $\mathrm{MMH}$ on academic outcomes, via permissive parenting, was significant (indirect $\beta=0.16, p=0.02$ ), and the direct effect of $\mathrm{MMH}$ was non-significant $(\beta=0.15, p=0.18)$, signifying that permissive parenting was a complete mediator of the effect of maternal mental health on academic outcomes.

Mediated effects of maternal functioning via components of permissive, punitive or authoritative parenting: After testing each of the four second-order latent parenting constructs for mediation, we examined each of the nine first-order components to determine if specific aspects of parenting were responsible for mediation of $\mathrm{MMH}$ effects, whether or not we had found mediation at the construct level. Three first-order components of the parenting constructs showed significant associations with maternal functioning and thereby met the first criteria for mediation: lack of follow-through and lack of parenting confidence (both from permissive parenting), and verbal hostility, a component of punitive authoritarian parenting. All associations were negative: mothers with better mental health reported less lack of follow-through $(\beta=-0.26, p<0.05)$, less lack of parenting confidence $(\beta=-0.45, p<0.001)$, and less verbal hostility $(\beta=-0.25, p<0.03)$. Of the three components, verbal hostility and lack of follow-through showed no significant effect on teen academic outcomes and therefore could not be mediators. Only lack of parenting confidence was associated with youth academic outcomes $(\beta=-0.36, p<0.01)$, thereby meeting the second criterion for mediation.

The direct and mediation models for lack of parenting confidence can be seen in Fig. 3. Even though the direct effects model (Fig. 3a) showed good fit to the data $\left(\chi^{2}(63)=78.17, p=0.09\right.$; $\mathrm{SRMR}=0.071 ; \mathrm{RMSEA}=0.038)$, fit was significantly improved $\left(\operatorname{LR} \chi^{2}(l)=7.11, p=0.008\right)$ by estimating the mediational path from lack of parenting confidence to academic outcomes (Fig. 3b). In addition, the indirect mediational effect was significant (indirect $\beta=-0.16$, $p<0.001)$. Moreover, in the mediational model, the direct effect of $\mathrm{MMH}$ on youth academic outcomes was no longer significant $(\beta=0.10, p=0.37)$, indicating that the effect was completely mediated by lack of parenting confidence.

\section{Discussion}

In our review of the literature and in the current data set, we find evidence that $\mathrm{MMH}$ functioning problems are associated with problematic parenting, permissive parenting generally and, particularly, lack of follow through and lack of parenting confidence, as well as a component of punitive parenting - verbal hostility. Although authoritative parenting is seen as the gold standard of parenting for white, middle class parents, its relationship with academic outcomes for low income and minority youths is unclear. Authoritative parenting was not correlated with $\mathrm{MMH}$ or academic outcomes in our study, and we found no evidence of a systematic association between maternal mental illness and authoritative parenting in the literature. In terms of effects of diagnosis, worse $\mathrm{MMH}$ functioning was related to bi-polar diagnosis; however, diagnosis itself had no direct effect on teen academic outcomes.

Permissive parenting generally, and lack of parenting confidence in particular were associated with worse academic outcomes; indeed lack of parenting confidence fully mediated the negative effect of poor maternal functioning on academic outcomes. This finding has important 


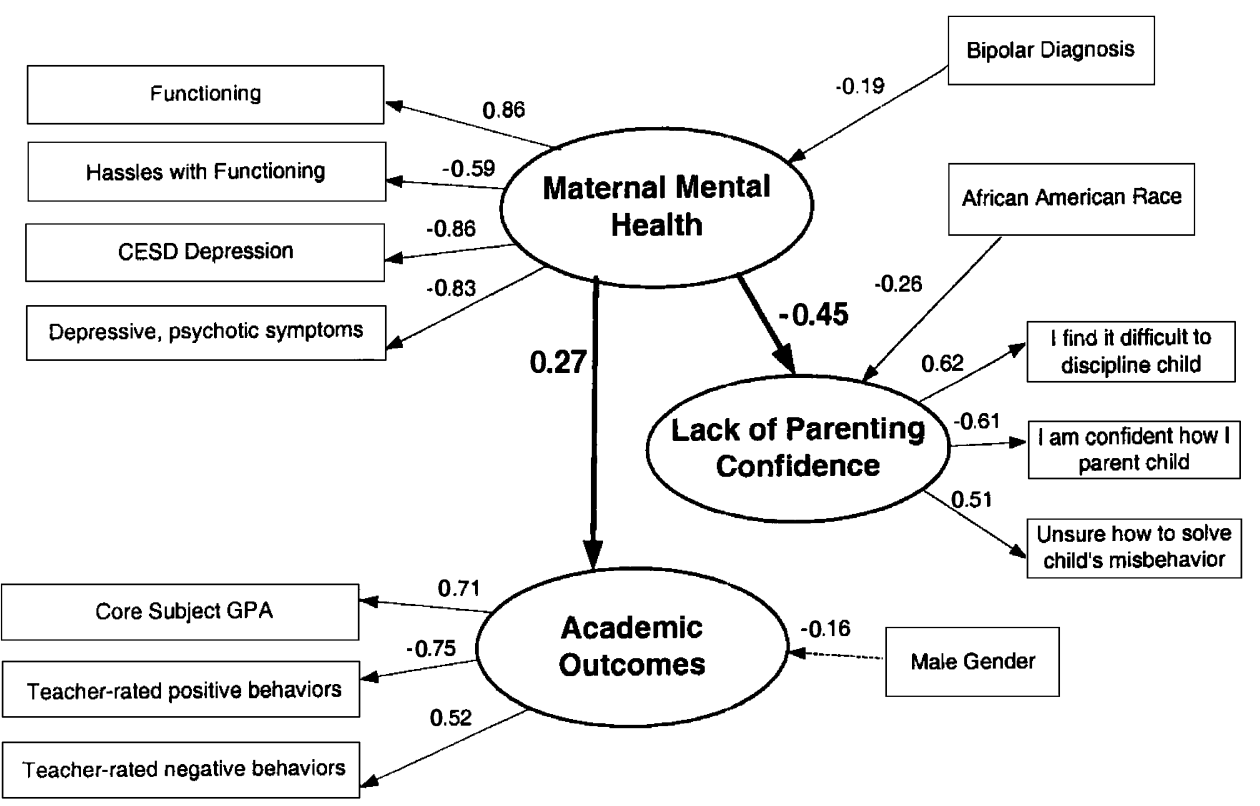

(a)

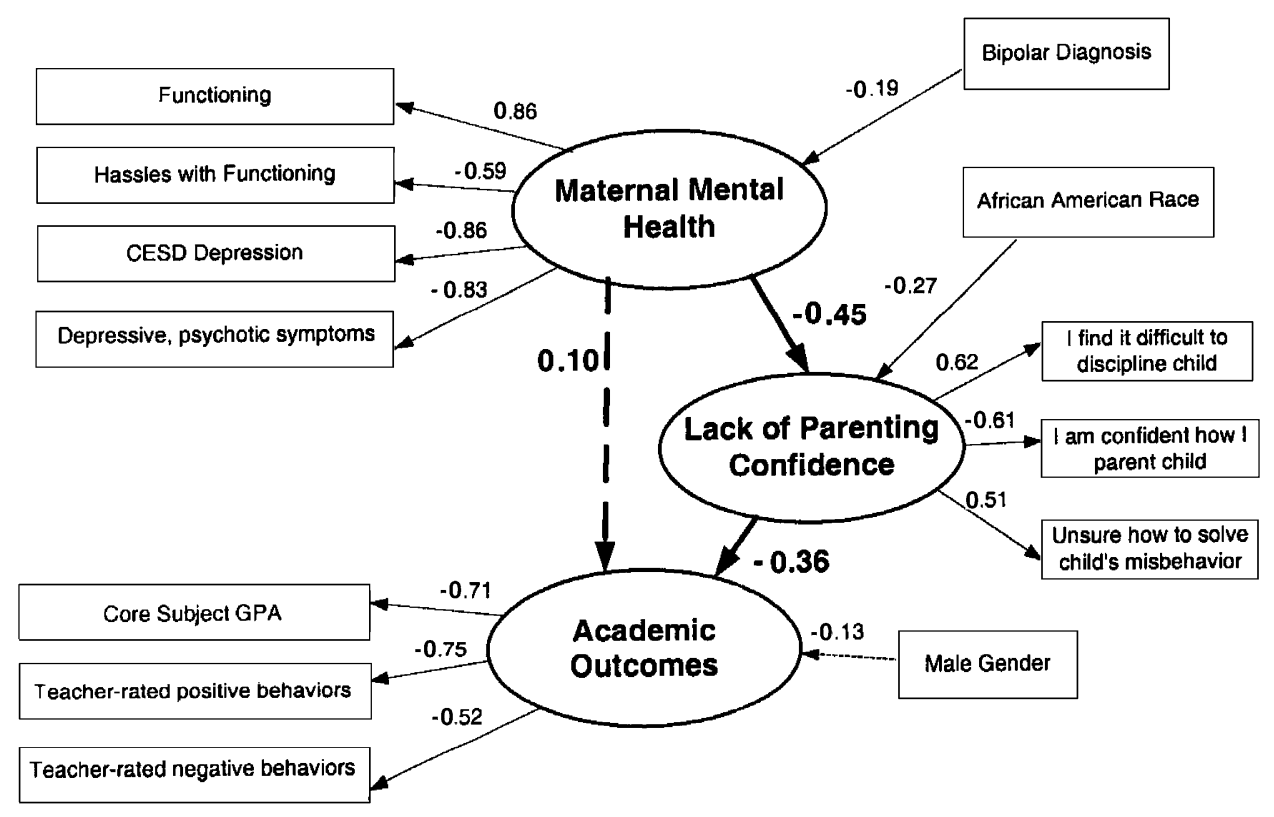

(b)

Fig. 3. Estimated models: effects of MMH on lack of parenting confidence and youth academic outcomes $(N=164$ mother-youth pairs). (a) direct effects model: $\chi^{2}(63)=78.17, p=0.09$; SRMR $=0.071$; RMSEA $=0.038$. (b) mediated effects model: $\chi^{2}(62)=71.06, p=0.20$; SRMR $=0.058$; RMSEA $=0.030$. Note: All coefficients are standardized. Solid lines indicate coefficients significant at $p<0.05$; dashed lines indicate non-significant coefficients. 
implications because it suggests that supporting mothers in their parenting could ameliorate negative effects of maternal mental illness. Moreover, all mothers in our sample had a diagnosis of serious mental illness yet varied in their current functioning in ways that influenced parenting; therefore supports should take into account variability in functioning.

The literature also suggests that stress increases components of authoritarian parenting, especially punitiveness (e.g. Webster-Stratton, 1990), and that mental illness can increase uncertainty about appropriate parenting. Transactional parenting models, in which parent-child interactions are key (see for example Pomeranz \& Eaton, 2001) suggest another possibilitymentally ill parents of adolescents may have particular difficulty because parent confidence may be undermined by teens' attempts to separate and individuate from their parents by mocking and ridiculing parent's illness.

Since components of authoritative parenting (warmth, nurturance, and appropriate control and demandingness) seem central to many discussions of parenting, we considered various possibilities for our lack of findings. First, as suggested by Roberts and Steinberg (1999) it is possible that authoritative parenting may have a curvilinear relationship with outcome variables; for example, demandingness and behavioural control may be positively associated with academic competence at moderate rather than high or low levels. We looked for and did not find such a non-linear relationship in our own data, using exploratory graphical analysis. Second, it is possible that we found effects of parenting confidence as a mediator of the negative effects of mental health problems on youth academic outcomes (but no mediation effects for the other parenting variables) because asking mothers about their confidence in parenting is a good way to assess this aspect of parenting, but other aspects of parenting related to authoritative practices are better measured in another way. Replicating previous research, we found that MMH related to verbal hostility; moreover, at the level of the parenting constructs, our finding that $\mathrm{MMH}$ did not influence directive, punitive authoritarian, or (warm) authoritative parenting is in line with research suggesting a genetic basis to maternal warmth-positivity and punitive-negativity and more environmental effects of maternal control and monitoring (see Neiderhiser et al., 2004). In this research, the authors compare results of two studies, one in which mothers who are twins are compared and another in which parental responses to twins are compared. In both cases, effects differ by reporter of parenting, with observer ratings showing the least relationship to genetic environment. Across all measures, however, a mother's attempts and success at controlling and monitoring her adolescent are not predicted by passive or non-passive genetic influences. Maternal negativity (parallel to the current punitiveness measure) seems evoked by teen temperament, while maternal positivity is evoked both by teen temperament and by maternal genetic background. Coupled with our findings, these results suggest that particular effort should be provided to support mothers in their efforts to parent under environmental stresses and with their particular teen and temperament.

Third, in light of Mize and Pettit's (1997) distinction between parenting style and practices, it is possible that general parenting efficacy might moderate the effects of the parenting subscales. We explored these issues in our sample, finding that parenting efficacy was positively correlated with authoritative parenting $(r=0.16, p=0.04)$ and negatively correlated with parenting uncertainty $(r=-0.18, p=0.02)$ and at a trend level was negatively correlated with permissive parenting $(r=-0.14, p=0.08)$, however, the correlations are quite low, suggesting that the constructs are not redundant. Indeed, in our data, parenting efficacy was not associated with teen academic 
outcomes. Moreover, we found that parenting efficacy of mothers with younger children, not yet teens, was significantly higher than the parenting efficacy of the mothers of teens, suggesting that parenting a teenager taxes mothers' ability to feel competent and confident of their skills.

Since evidence for effects of authoritative parenting typically come from youth report data, it is possible that the positive association found in the literature is due to operationalization of authoritative parenting in terms of youth perception of the mother as warm, appropriately involved, and appropriately demanding - it may not be the mother's report of her intent, but the teen's perception of intent that matters. It is not clear to what extent maternal and youth report overlap on this aspect of parenting, and it may be that the youth's opinion as to warmth, involvement, and demandingness are particularly important. For example, mothers may feel warm and involved when youth find them to be intrusive and controlling.

Pomerantz and Eaton (2001) provide the following instructive example of a parent who asks to check over a homework when the child does not ask for such help; the parent may intend to convey caring and valuation of academics through such behavioural control, the child may perceive that their autonomy is being suppressed (a form of psychological control posited to have negative consequences). Indeed, Lanz, Scabini, Vermulst, and Gerris (2001) find only moderate agreement between parent's and children's perceptions of parenting style, leaving open the question as to whose perception is more predictive of which outcomes. In preliminary analyses with our own data, we explored whether youth report or maternal report of parenting was a better predictor of school-reported youth academic outcomes (e.g. GPA and teacher report of behaviour) and found better association with maternal parenting report than with youth parenting report; other research showing relationships with youth report of parenting may also use youth report of academic outcomes (e.g. Paulson, 1994).

Another concern is whether in using the PPQ, we are measuring parenting practices"strategies undertaken to achieve specific goals in specific contexts or situations" (Pomeranz \& Eaton, 2001, p. 175) or parenting styles - "parent-child interactions over a wide range of situations and that are presumed to create a pervasive interactional climate" (Pomeranz \& Eaton, 2001, p. 175), or parent beliefs (Darling \& Steinberg, 1993). As these authors note, though conceptually distinct, these levels are difficult to separate empirically. Therefore, a conservative approach is useful-our results should be interpreted in terms of the specific aspects of parenting that were assessed by the measures used.

Our study has a number of strengths. To our knowledge, our study is unique in its use of a high risk sample, multiple lagged time points for maternal data and multiple outside sources for teen academic outcomes. We focus on a highly stressed sample, including both minorities and individuals with low income as well as mental health problems. Thus, our findings are clearly relevant to high-risk samples. In addition, we focused on parenting subscales that were race invariant so that the effects apply to both black and white parents. However, a number of limitations should also be noted. Although large relative to other research on effects for children of mothers with a mental illness, our sample size still placed limits on our ability to find effects. Effects needed to be relatively robust for us to find them. Further, though mothers in our sample vary in mental health functioning, all have a mental illness, limiting the range of variation in mental health functioning and thereby reducing the strength of relationship between mental health functioning, parenting and academic outcomes. 
Third, by focusing on women who had both low incomes and mental health problems; it is possible that we limited effects for authoritarian and authoritative parenting - in more middle class and less stressed groups, we might have found positive effects of authoritative and negative effects of authoritarian parenting on academic outcomes. Fourth, we are unable to perform longitudinal analyses of either the effects of change in mental health on change in parenting practices or the effects of change in mental health and parenting on change in academic outcomes since our longitudinal data did not include repeated measures of parenting practices or academic outcomes. Fifth, although we assessed parenting practices prior to obtaining school records, it is possible that there is a cyclical effect, with mothers become increasingly uncertain how to parent when their children are not succeeding in school.

Lastly, we focused on the mediating effects of maternal parenting rather than parenting from a father figure. It is possible that if either parent parents well, academic outcomes are bolstered. Indeed, Chen, Liu, and Li (2000) find maternal and paternal parenting style to have different effects, while Mattanah (2001) also points to the importance of fathers. Given that many of the teens in our sample were living in households without fathers, obtaining paternal reports would have required significant additional investment.

Although we did not have diagnostic information on other adults in our study, we were able to look at involvement of fathers. In separate MANCOVA analyses, we did find effects on academic outcomes of (youth reported) father involvement and support - having a relationship with one's father is related to better GPA and at trend level, less negative in-school behaviour by teacher report. Among those who have a relationship, those with a positive relationship do best, those with no relationship to their father do marginally better than those with a negative relationship with fathers. Thus, future analysis of the mediating effect of parenting practices might be enhanced if parenting of both parents were assessed.

That said, our finding of effects based on maternal parenting has clear applied implications. It points to the importance of malleable aspects of the child's experience - maternal parenting practices, especially the ability to maintain a sense of confidence in one's parenting, in mediating other negative effects on academic outcomes of youths living in high risk environments due to the combination of poverty and maternal mental illness. Given the severity of MMH problems in the group studied, these results are cause for optimism.

\section{Acknowledgements}

We would like to thank participating parents and youth as well as our interview coordinator, Angelique Lange and our interviewers.

\section{References}

Arbuckle, J. L., \& Wothke, W. (1999). AMOS 4.0 user's guide. Chicago: Small Waters.

Aunoloa, K., Stattin, H., \& Nurmi, J.-E. (2000). Parenting styles and adolescents' achievement strategies. Journal of Adolescence, 23, 205-222. 
Baumrind, D. (1991). Parenting styles and adolescent development. In J. Brooks-Gunn, R. Lerner, \& A. C. Petersen (Eds.), The Encyclopedia of Adolescence (pp. 746-758). New York: Garland.

Baron, R. M., \& Kenny, D. A. (1986). The moderator-mediator variable distinction in social psychological research: conceptual, strategic, and statistical considerations. Journal of Personality and Social Psychology, 51, $1173-1182$.

Bentler, P. M., \& Wu, E. J. C. (1995). EQS for Windows: user's guide. Encino, CA: Multivariate Software.

Billings, A. G., \& Moos, R. H. (1983). Comparisons of children of depressed and nondepressed parents: a socioenvironmental perspective. Journal of Abnormal Child Psychology, 11, 463-485.

Brown, R. L. (1997). Assessing specific mediational effects in complex theoretical models. Structural Equation Modeling, 4(2), 142-156.

Buckley, P. F., Buchanan, R. W., Schulz, S. C., \& Tamminga, C. A. (1996). Catching up on schizophrenia: the fifth international congress on schizophrenia research, Warm Springs, VA, April 8-12, 1995. Archives of General Psychiatry, 53, 456-464.

Bybee, D., Mowbray, C. T., Oyserman, D., \& Lewandowski, L. (2003). Variability in community functioning of mothers with serious mental illness. Journal of Behavioural Health Services and Research, 30, 273-293.

Byrne, B. M., Shavelson, R. J., \& Muthen, B. (1989). Testing for the equivalence of factor covariance and mean structures: the issue of partial measurement invariance. Psychological Bulletin, 105, 456-466.

Chen, X., Liu, M., \& Li, D. (2000). Parental warmth, control, and indulgence and their relations to adjustment in Chinese children: a longitudinal study. Journal of Family Psychology: Special Issue: Cultural Variation in Families, 14, 401-419.

Coleman, P. K., \& Karraker, K. H. (1997). Self-efficacy and parenting quality: findings and future applications. Developmental Review, 18, 47-85.

Coleman, P. K., \& Karraker, K. H. (2000). Parenting self-efficacy among mothers of school-age children: conceptualization, measurement, and correlates. Family Relations, 49, 13-24.

Cutrona, C. E., \& Troutman, B. R. (1986). Social support, infant temperament, and parenting self efficacy: a mediational model of postpartum depression. Child Development, 57, 1507-1518.

Darling, N., \& Steinberg, L. (1993). Parenting style as context: an integrative model. Psychological Bulletin, 113, 487-496.

Davies, P. T., \& Windle, M. (1997). Gender-specific pathways between maternal depressive symptoms, family discord, and adolescent adjustment. Developmental Psychology, 33, 657-668.

Dornbusch, S. M., Ritter, P. L., Leiderman, H., Roberts, D. F., \& Fraleigh, M. J. (1987). The relation of parenting style to adolescent school performance. Child Development, 58, 1244-1257.

Downey, G., \& Coyne, J. C. (1990). Children of depressed parents: an integrative review. Psychological Bulletin, 108, $50-76$.

Finn, J. D., Pannozzo, G. M., \& Voelkl, K. E. (1995). Disruptive and inattentive-withdrawn behaviour and achievement among fourth graders. The Elementary School Journal, 95, 421-434.

Garber, J., \& Little, S. (1999). Predictors of competence among offspring of depressed mothers. Journal of Adolescent Research, 14, 44-71.

Gelfand, D. M., \& Teti, D. M. (1990). The effects of maternal depression on children. Clinical Psychology Review, 10, 329-351.

Hahn, S. E., \& Smith, C. S. (1999). Daily hassles and chronic stressors: conceptual and measurement issues. Stress Medicine, 15, 89-101.

Hammen, C. (1997). Children of depressed parents: the stress context. In S. A. Wolchik (Ed.), Handbook of children's coping: linking theory and intervention (pp. 131-157). New York, NY: Plenum Press.

Hammen, C., Adrian, C., Gordon, D., Burge, D., Jaenicke, C., \& Hiroto, D. (1987a). Children of depressed mothers: maternal strain and symptom predictors of dysfunction. Journal of Abnormal Psychology, 96, 190-198.

Hammen, C., Gordon, D., Burge, D., Adrian, C., Jaenicke, C., \& Hiroto, D. (1987b). Maternal affective disorders, illness, and stress: risk for children's psychopathology. American Journal of Psychiatry, 144, 736-741.

Holden, G., \& Miller, P. (1999). Enduring and different: a meta-analysis of the similarity in parent's child rearing. Psychological Bulletin, 125, 223-254. 
Holmbeck, G. N. (1997). Toward terminological, conceptual, and statistical clarity in the study of mediators and moderators: examples from the child-clinical and pediatric psychology literatures. Journal of Consulting and Clinical Psychology, 65, 599-610.

Hoyle, R. H., \& Kenny, D. A. (1999). Sample size, reliability, and tests of statistical mediation. In R. H. Hoyle (Ed.), Statistical strategies for small sample research (pp. 195-222). Thousand Oaks, CA: Sage.

Hu, L. T., \& Bentler, P. M. (1995). Evaluating model fit. In R. H. Hoyle (Ed.), Structural equation modeling: concepts, issues, and applications (pp. 76-99). Thousand Oaks, CA: Sage.

Hu, L. T., \& Bentler, P. M. (1998). Fit indices in covariance structure modeling: sensitivity to underparameterized model misspecification. Psychological Methods, 3, 424-453.

Hu, L. T., \& Bentler, P. M. (1999). Cutoff criteria for fit indexes in covariance structure analysis: conventional criteria versus new alternatives. Structural Equation Modeling, 6, 1-55.

Lanz, M., Scabini, E., Vermulst, A. A., \& Gerris, J. R. M. (2001). Congruence on child rearing in families with early adolescent and middle adolescent children. International Journal of Behavioural Development: Special Issue, 25, $133-139$.

Lazarus, R. S., \& Folkman, S. (1984). Stress, appraisal, and coping. New York: Springer.

Little, R. J. A., \& Rubin, D. B. (1990). The analysis of social science data with missing values. In J. Fox, \& J. S. Long (Eds.), Modern methods of data analysis (pp. 374-409). Newbury Park, CA: Sage.

Maccoby, E. E., \& Martin, J. A. (1983). Socialization in the context of the family: parent-child interaction. In P. H. Mussen (Series Ed.) \& E. M. Hetherington (Vol. Ed.) Handbook of child psychology: Vol. 4. Socialization, personality, and social development (4th Ed., pp. 1-101). New York: Wiley.

MacKinnon, D. P., Lockwood, C. M., \& Williams, J. (2004). Confidence limits for the indirect effect: distribution of the product and resampling methods. Multivariate Behavioural Research, 39(1), 99-128.

Mardia, K. V. (1985). Mardia's test of multinormality. In S. Kotz, \& N. L. Johnson (Eds.), Encyclopedia of statistical sciences (Vol. 5, pp. 217-221). New York: Wiley.

Mattanah, J. F. (2001). Parental psychological autonomy and children's academic competence and behavioural adjustment in late childhood: more than just limit-setting and warmth. Merrill-Palmer Quarterly: Special Issue, 47, 355-376.

McLoyd, V. C., Jayaratne, T. E., Ceballo, R., \& Borquez, J. (1994). Unemployment and work interruption among African American single mothers: effects of parenting and adolescent socioemotional functioning. Child Development, 65, 562-589.

Mize, J., \& Pettit, G. (1997). Mothers' social coaching, mother-child relationship style, and children's peer competence: is the medium the message? Child Development, 68, 312-332.

Mowbray, C., Oyserman, D., \& Ross, S. R. (1995). Parenting and the significance of children for women with a serious mental illness. Mental Health Administration, 22, 189-200.

Neiderhiser, J., Reiss, D., Pedersen, N., Lichtenstein, P., Spotts, E., Hansson, K., Cederblad, M., \& Elthammer, O. (2004). Genetic and environmental influences on mothering of adolescents: a comparison of two samples. Developmental Psychology, 40, 335-351.

Onatsu-Arvilommi, T. P., \& Nurmi, J.-E. (1997). Family background and problems at school and in society: the role of family composition, emotional atmosphere and parental education. European Journal of Psychology of Education, $12,315-330$.

Oyserman, D., Mowbray, C. T., Allen-Meares, P., \& Firminger, K. (2000). Parenting among mothers with a serious mental illness. American Journal of Orthopsychiatry, 70, 296-315.

Patock-Peckham, J. A., Cheong, J., Balhorn, M. E., \& Nagosni, C. T. (2001). A social learning perspective: a model of parenting styles, self-regulation, perceived drinking control, and alcohol use and problems. Alcoholism: Clinical and Experimental Research, 25, 1284-1292.

Paulson, S. E. (1994). Relations of parenting style and parental involvement with ninth-grade students' achievement. Journal of Early Adolescence: Special Issue: Middle grades schooling and early adolescent development: I. Early adolescents' psychological characteristics, relationships with others, and school performance, 14, 250-267.

Peters, M. F. (1988). Parenting in Black families with young children: a historical perspective. In H. P. McAdoo (Ed.), Black families (2nd Ed., pp. 228-241). Thousand Oaks, CA: Sage. 
Pittman, L. D., \& Chase-Lansdale, P. L. (2001). African American adolescent girls in impoverished communities: parenting style and adolescent outcomes. Journal of Research on Adolescence, 11, 199-224.

Pomerantz, E., \& Eaton, M. (2001). Maternal intrusive support in the academic context: transactional socialization processes. Developmental Psychology, 37, 174-186.

Radloff, L. S. (1977). The CES-D Scale: a self-report depression scale for research in the general population. Applied Psychological Measurement, 1, 385-401.

Randolph, S. M. (1995). African American children in single-mother families. In B. J. Dickerson (Ed.), African American single mothers: understanding their lives and families (pp. 117-145). Thousand Oaks, CA: Sage.

Roberts, M., \& Steinberg, L. (1999). Unpacking authoritative parenting: reassessing a multidimensional construct. Journal of Marriage and the Family, 3, 574-587.

Robins, L. N., Helzer, J. E., Croughan, J., \& Ratcliff, K. S. (1981). National Institute of Mental Health Diagnostic Interview Schedule: its history, characteristics, and validity. Archives of General Psychiatry, 38, 381-389.

Robinson, C. C., Mandleco, B., Olsen, S. F., \& Hart, C. H. (1995). Authoritative, authoritarian, and permissive parenting practices: development of a new measure. Psychological Reports, 77, 819-830.

Saugstad, L. F. (1989). Social class, marriage, and fertility in schizophrenia. Schizophrenia Bulletin, 15, 9-43.

Schafer, J., \& Graham, J. W. (2002). Missing data: our view of the state of the art. Psychological Methods, 7, 147-177.

Shern, D. L., Wilson, N. Z., Coen, A. S., Patrick, D. C., Foster, M., Bartsch, D. A., \& Demmler, J. (1994). Client outcomes II: longitudinal client data from the Colorado Treatment Outcome Study. The Milbank Quarterly, 72, $123-148$.

Shrout, P. E., \& Bolger, N. (2002). Mediation in experimental and nonexperimental studies: new procedures and recommendations. Psychological Methods, 7(4), 422-445.

Tannenbaum, L., \& Forehand, R. (1994). Maternal depressive mood: the role of the father in preventing adolescent problem behaviours. Behaviour Research Therapy, 32, 321-325.

Taylor, L. C., Hinton, I. D., \& Wilson, M. N. (1995). Parental influences on academic performance in African American students. Journal of Child \& Family Services, 4, 293-302.

US Census Bureau (1996). Poverty thresholds in 1995, by size of family and number of related children under 18 years. US Census Bureau, Current Population Survey. Bureau of the Census, Washington, DC.

US Department of Health \& Human Services (1999). Mental health: a report of the surgeon general. Retrieved June 20, 2003 from http://www.surgeongeneral.gov/library/mentalhealth/pdfs/front.pdf

Webster-Stratton, C. (1990). Stress: a potential disruptor of parent perceptions and family interactions. Journal of Clinical Child Psychology, 19, 302-312. 